\title{
A REVIEW OF METHODS FOR ASSESSING THE POTENTIAL RISKS IN URBAN PASSENGER TRANSPORT
}

\author{
Alexandru-Mihai Bugheanu ${ }^{251}$ \\ Bogdan-Stefan Stoica ${ }^{252}$ \\ https://doi.org/10.31410/itema.2018.660
}

\begin{abstract}
The importance of public transportation networks implies the necessity of identifying potential risks that could negatively influence the quality of the services. Public transport networks are very developed in Romania, 22\% of the individuals using public transport daily, compared with an average of 16\% in the European Union for 2017.

The main objective of the current paper is to present some of the risks to which passengers are exposed along with the effects on the quality of transport services.

Accordingly, the purpose of this article is to present an extensive research of the specialized literature in the field of risks in public transport systems.

The key findings of this study is the fact that identifying the risks to which passengers are exposed should be one of the priorities for any public transport operator or public administration. All things considered, authorities should ensure a gradual increase in terms of effectiveness and efficiency for the public transport services.
\end{abstract}

Keywords: public transport, risk management, urban life quality, strategies.

\section{INTRODUCTION}

owadays, the efficiency of public transport systems all over the world directly $\mathrm{N}$ influences the quality of urban life. One of the biggest challenges for any urban transport service is to succeed in overcoming individuals preferences for using private means of transit. Furthermore, transport systems must ensure their sustainability, which translates by less energy consumption and improving land infrastructure investments [1].

In the current economy, the transport sector is responsible for having a major impact on societies and also on the environment as the principal mode of transportation. At the same time, is the most oil-consuming industry and an important factor for greenhouse gases. Specifically, [2] estimates that this sector will account for more than $50 \%$ of the oil consumption in 2020, as well as causing approximately $25 \%$ of the $\mathrm{CO}_{2}$ emissions.

Under those circumstances, the consequences of transport risks may severely affect the quality of the public transport services, especially in a heavily developed urban area like Bucharest, a city with an average population of about 3 million people.

The current paper will be the foundation of an extensive research whose purpose will be reducing the risk in the public transport networks in Romania' capital - Bucharest. The aim of

\footnotetext{
${ }^{251}$ Bucharest University of Economic Studies, Piata Romana No.6, Bucharest, Romania

${ }^{252}$ Doctoral School of Management, Bucharest University of Economic Studies, Piata Romana No.6, Bucharest, Romania
} 
the present study is to display a substantial research of the specialized literature in the field of risks in public transport networks.

Given these points, this study is presented as a starting point for extensive research on the public transport threats, alongside with potential risk management measures.

First of all, in order to examine to risks that could occur in public transport system we should concentrate on the characteristics that are important for passengers. Specifically, on the quality indicators of a public transport network, listed below:

- Service reliability;

- Travel speed;

- Network coverage;

- Safety and security for passengers, on board and also on the transport stations ;

- Comfort: seating availability, space in the transport modes, cleanliness;

- Separated lanes for buses and trams;

- Affordable tickets;

- Convenient walking distance from transport stops ;

- Short waiting time in transport stops ;

- Reliable and precise timetables;

- Transit interchanges stops;

- Services for disabled people.

Consequently, we need to analyze how different risk could occur in these situations, and how this aspects will affect the passengers overall satisfaction.

As well known, road transportation in general and specifically public transport involves certain threats for individuals concerning their comfort, trip satisfaction, or even their health.

\section{DISCUSSION ON THE GENERAL RISKS THAT CAN OCCUR IN PUBLIC TRANSPORT}

A very important category of risks that could occur is related to traffic congestion as well as road accidents. Reducing the impact on public transport users should be one of the primary objectives for any transport operator or administration.

Correspondingly, public transport modes can be involved in serious road accidents which may endanger the health and integrity of passengers. According to [3] road accidents can be classified into the following categories:

1. Accidents between transport vehicles. Here we can include frontal collisions, frontallateral, lateral, rear-end and collisions with stopped vehicles.

2. Accidents involving a single vehicle.

3. Accidents involving pedestrians.

In addition to these types of accidents, we should also analyze some of the underlying causes of their production. With this in mind, we can present a number of categories factors with major influence on public transport vehicles accidents:

- Technical faults: poor vehicle maintenance

- Weather conditions;

- Road characteristics;

- Road user's behavior: reckless driving, excess speeding, driver fatigue;

- Unforeseen random events. 
On the other hand, at the present time, World Health Organization confirms that more than 40 million people in the European Union, from the largest 115 cities are exposed daily to highly polluted air [4].

With this in mind, according to the European Commission, urban transport operators and administrations must concentrate on three important challenges:

1. Climate warning. The greenhouse gases emission should be decreased by 2030 with $40 \%$ compared to 1990 .

2. Individual's safety and security. This aspect can be improved through a better road infrastructure and automatic traffic management.

3. Aging population. Promoting elderly people' mobility should be dramatically increased.

All things considered, different solutions using buses are considered the most efficient way for passenger's transportation in terms of energy consumption [5].

\section{LITERATURE REVIEW}

Regarding the study of the specialized literature, a clear distinction must be made between the theoretical research and practical applications or simulations. This distinction is necessary because testing new projects in the field of public transportation is an extremely expensive practice. In either case, it is not accessible for any group of researchers or sometimes even to public authorities.

With this in mind, in 2012 the International Organization for Standardization introduced ISO 39001:2012 the Road Traffic Safety (RTS) Management System, which aims to be a "practical tool for governments, vehicle fleet operators and all organizations worldwide who want to reduce death and serious injury due to road accidents. ISO 39001 provides them with state-ofthe-art requirements for safety aspects including speed, vehicle condition and driver awareness" [6], [7].

Therefore, ISO 39001 is perceived as a significant contribution to the United Nation's Decade of Actions for Road Safety for the 2011-2020 period because it imposes new quality standards and also it provides a lot of know-how in the field of public transportation risks. An important key point to realize is the fact that the standard was designed with the support of experts from a total of 40 countries, as well as world-renowned organizations such as World Health Organizations or the World Bank.

All things considered, among the measures imposed by the new standard are included: transport mode specifications, braking systems aspects, protection measures in case of impact, new aspects of ergonomics and so on. Given these points, the new standard will have a significant impact of future traffic safety statistics and thus decreasing passenger's risks for severe injuries. Equally important, it will increase users' satisfaction and the overall quality of the public transport systems.

Specifically, regarding traffic congestion that is a worldwide phenomenon specialized literature [8] defines two types of congestion:

a) Recurrent congestion, when it depends directly on normal traffic conditions;

b) Non-recurrent congestion, when is due to external factors, difficult to predict such as accidents, extreme weather or natural disasters. 
As a result, traffic congestion is closely associated with transit risks, but it is difficult to quantify such a relationship due to a lack of data and mathematical models. Particularly, data unavailability is accentuated when it comes to public transportation of passengers. Nevertheless, researchers have developed mathematical models and algorithms to evaluate transport accidents frequency from a risk management approach.

As an illustration, [9] studied an algorithm in order to calculate the frequency of an accident on the particular road:

$$
\begin{gathered}
\mathrm{f}_{\mathrm{i}}=\mathrm{y}_{\mathrm{i}} \mathrm{L}_{\mathrm{i}} \mathrm{n}_{\mathrm{i}} \\
\mathrm{y}_{\mathrm{i}}=\mathrm{y}_{0} \sum_{\mathrm{j}=1}^{6} \mathrm{~h}_{\mathrm{j}}, \text { where: }
\end{gathered}
$$

- $\mathrm{y}_{\mathrm{i}}=$ the expected frequency on the $\mathrm{i}$ road;

- $\mathrm{L}_{\mathrm{i}}=$ the road length;

- $\mathrm{n}_{\mathrm{i}}=$ the vehicle number;

- $\mathrm{y}_{0}=$ the basic frequency;

- $\mathrm{h}_{\mathrm{j}}=$ the mitigating parameters.

As a result, the researcher concluded that these are the most important parameters that can influence road accidents constantly. Therefore, these aspects should be carefully analyzed by any transport authority or public administration.

Likewise, specialized literature develops the concept of intelligent transport systems (ITS) [10], [11] which can help overcome some of the public transportation problems by enhancing the overall efficiency. In particular, risk management, which includes risk prevention is one of the most significant components of a ITS program, due to the fact that allows operators to identify, group and analyze serious risks [12].

An exploratory research on intelligent transport systems was realized by [12] in order to identify and analyze the necessary steps to create an assessment methodology for an ITS program. In the author' opinion the following stages are required:

1. Planning the initiation of a ITS program. In detail, through this component is being pursued different action which can drastically eliminate various risks and also minimizing their consequences: threats assessment, general research.

2. Risks selection. In other words, the transport risks will be defined as well as determining the resulted threats.

3. Risks analysis. Previously identified risk will be thoroughly analyzed. In addition, in this stage the researcher will study risks impact on the overall performance of the transport system.

4. Taking necessary measures. At this stage the decision maker will identify control measures and monitor the risks through online control.

5. Creating a mitigation plan. As a result, there will be developed the necessary tools to cope and respond to any transport situation.

6. Creating mitigation scenarios to risk outcomes. To put it another way, there will be analyzed aspects such as cooperation between public administrations and private operators, infrastructure features, important trend in ITS development.

As has been noted, the authors considers the introduction of an ITS program mandatory for any effective transportation system, thus achieving a better risk management and control, while in the same time improving the service quality. 
At the same time, in addition to introducing an ITS management program, the highly developed cities around the world analyzes the concept of fully automated public transport vehicles. [13] have studied the implementation of an Automated Demand Responsive Transport System (ADRTS) in Arnhem-Netherlands, which should substitute traditional public transport modes with completely automated vehicles. An ADRTS involves a service responsive to users demand.

In other words, passengers should request a vehicle to a certain transport station. In this case, an automated transport vehicle, which is either stationed or in traffic should sort the passengers request and assign the task to one of the vehicles from the transport fleet.

In the long run, this modern project aims to reduce the overall transportation costs by:

1. Optimizing vehicles assignment;

2. Stationing transport modes when there are no passengers requests;

3. Reducing the transport fleet.

The analysis was based on a city in the Netherlands-Arnhem, a city with a population of approximately 150.000 people. The researchers tested 21 different scenarios in the final analysis simulating aspects such as:

- Vehicles passengers capacity (2-40 users per trip);

- Initial vehicles location;

- Demand level;

- Vehicles dwell time.

In the final analysis, the operations cost for the normal transport system in Arnhem were compared to the best scenario case for an ADRTS system. For example, for the current infrastructure, the public administration registers a cost of $0.68 €$ per passenger/trip with the bus.

On the other hand, using an automated vehicle, the authors estimated a final cost of $0.63 €$ per trip for a passenger. Meanwhile, the operation costs were calculated without taking into consideration the drivers salaries for the normal operated transport network, which will increase the cost by almost $300 \%$, due to a cost of $25 €$ per hour/driver. In other words, the total cost for a normal bus trip increases from 0.68 to $3.24 €$.

Under those circumstances, automated public vehicles can be a sustainable solution in the future, as well as an alternative to diminish operation costs.

In addition, more advanced studies on this topic can be found in the research papers from [14], who studied the effect of traffic risk in Warsaw, the biggest city in Poland. The authors presented the TRAQM method - Traffic risk assessment quantitative method, which divides risk into different categories based on their determinants and consequences. Furthermore, they developed the following strategies, based on management methodologies in order to raise awareness of risk levels in public transport:

1. Avoiding risks if possible;

2. Reducing risks, by proactive operations which will limit the threats;

3. Fallback, minimizing the risks probabilities;

4. Transferring the risks responsibilities if possible to other parts that can deal better with certain threats;

5. Sharing the identified negative aspects with other entities; 
6. Accepting the risks, when countermeasures cannot be identified or justified financially.

As can be seen, in the researchers opinion' it is absolutely mandatory for any administration to design a risk strategy in the field of transportation and to offer framework solutions [14].

\section{CONCLUSIONS}

Public transport is by definition a safe, reliable and economical mode of transportation. As a result, millions of people uses public transit systems daily, and the number is in a continuously increase each year. At the same time, these aspects also means that accidents involving transport vehicles may often include various injuries for the passengers.

Even if public transport unfortunate casualties are much less common than accidents involving private vehicles, the effect can be just as devastating.

This paper presents a first stage in analyzing some of the threats and risks in public transportation of passengers, and how transport operator or public authorities worldwide dealt with these challenges.

In the long run, risks and threats decreasing should be an important objective for any transport operator. Their main attention must be focused on reducing the consequences, having an active risk approach, as well as developing a risk assessment methodology. As a result, traffic safety can be improved alongside with passenger security and comfort.

All things considered, planning and managing future public transport networks will be more complex than in the past. Henceforth, new studies and methodologies should be elaborated and applied in order to increase user' satisfaction and the overall quality of the services.

\section{FURTHER RESEARCH}

In continuation to this study, there will be realized series of papers in order to provide new insights on:

- the public transport systems in Romania;

- risk management in transit systems;

- various threats than can affect the passengers.

The main objective is to gather relevant information and data on this topic. Thus, being able to conduct a research that could developed a risk assessment methodology in the field of public transportation.

\section{ACKNOWLEDGEMENT}

"'This study was conducted through the post-doctoral advanced research studies for the academic years 2018-2020, Management field, coordinator The Bucharest University of Economic Studies". 


\section{REFERENCES}

[1] Malasek, Jacek. (2016) A set of tools for making urban transport more sustainable, 6th Transport Research Arena, available at Transportation Research Procedia 14 ( 2016 ), pp. 876-885.

[2] International Energy Agency. (2002) Bus systems for the future. Achieving sustainable transport worldwide, IEA Publications, Paris, pp. 17-18.

[3] Conca A., Ridella C., Saporiz E. (2016) A risk assessment for road transportation of dangerous goods: a routing solution, 6th Transport Research Arena, available at Transportation Research Procedia 14, pp. 2890 - 2899.

[4] MyWay. (2015) Multi-modal journey planning made easy to encourage the use of sustainable modes of transport. Available at: www.myway-project.eu.

[5] International Energy Agency. (2009) Transport, energy and CO2. Moving toward sustainability, IEA Publications, Paris, pp. 52-54.

[6] International Organization for Standardization. (2012), ISO road safety standard could help save thousands of lives, available at https://www.iso.org/news/2012/10/Ref1661.html.

[7] International Organization for Standardization. (2012), Road traffic safety (RTS) management systems -- Requirements with guidance for use, available at https://www.iso.org/standard/44958.html.

[8] Conca A., Ridella C., Saporiz E. (2016) A risk assessment for road transportation of dangerous goods: a routing solution, 6th Transport Research Arena, available at Transportation Research Procedia 14, pp. 2890 - 2899.

[9] Fabiano, B., Palazzi, E., Currò, F., Pastorino, R. (2002) A framework for risk assessment and decision-making strategies in dangerous good transportation, Journal of Hazardous Materials, Volume 93, pp. 1-15, ISSN 0304-3894.

[10]Nazer Z., Jaffe R. (2006) Regional ITS Architecture for London Olympics, Proceedings of 13th ITS World Congress, London.

[11]Darido G., Osama T., Schneck D. (2003) The Role for ITS in Transport Planning and Operations of Olympic Events: Case Studies and Lessons Learned, Proceedings of 10th World Congress Intelligent Transport Systems and Services, Madrid.

[12] Olga Krivolapova. (2017) Algorithm for Risk Assessment in the Introduction of Intelligent Transport Systems Facilities, 12th International Conference "Organization and Traffic Safety Management in large cities", available at Transportation Research Procedia 20, pp. 373-377.

[13] Winter, K., Cats O., Correia G., Arem van B. (2018), Performance analysis and fleet requirements of automated demand-responsive transport systems as an urban public transport service, International Journal of Transportation Science and Technology 7, pp. 151-167.

[14]Koziol, J., Gromek, P.(2017), Creating safety in transport - traffic risk approach, TRANSCOM 2017: International scientific conference on sustainable, modern and safe transport, available at Procedia Engineering 192, pp. 457-462. 